\title{
Influence of water to solid ratio on mechanical properties of GBFS-based geopolymer foam concrete
}

\author{
Tomasz Piotrowski ${ }^{1, *}$, and Piotr Prochon ${ }^{1}$ \\ ${ }^{1}$ Warsaw University of Technology, Faculty of Civil Engineering, Al. Armii Ludowej 16, \\ 00-637 Warsaw, Poland
}

\begin{abstract}
The development of sustainable building materials with reduced environmental footprint in both, manufacturing and operational phases of the material lifecycle, is attracting increased interest in the construction industry worldwide. A recent innovation, the geopolymer foam concrete, combines the performance benefits and operational energy savings achievable through the use of lightweight foam concrete, with the cradle-togate emissions reductions obtained through the use of a geopolymer binder derived from granulated blast-furnace slag (GBFS). In this study mechanical properties of GBFS-based foam concrete were investigated for samples of different water to solid ratio $(0.252,0.287$ and 0.321$)$. According to ASTM C 796-97 both mass of the foaming solution and water in sodium silicate solution was considered as part of the total amount of mixing water. As a solid part, GBFS and solid part of activators $(\mathrm{NaOH}$ and sodium silicate) was accounted. A group of specimens $(40 \times 40 \times 160$ beams and $100 \times 100 \times 100$ cubes) have been prepared and volume density, bending, compressive strength tests have been performed. In a result an optimized lightweight GBFS-based geopolymer foam concrete was obtained, characterized by 1.8 $\mathrm{kg} / \mathrm{dm} 3$ volume density, $2.6 \mathrm{MPa}$ bending strength and $51.8 \mathrm{MPa}$ compressive strength measured on beams and $44.1 \mathrm{MPa}$ compressive strength on cubes.
\end{abstract}

\section{Introduction}

The name "geopolymers" was introduced by J. Davidovits to describe "mineral polymers" obtained in the way of geosynthesis or geochemistry 0 . Those amorphous polymers are formed by mixing an aluminosilicate raw material with aqueous alkali solution 2 . To obtain geopolymer composites of certain properties, one needs to select particular raw material, mix it with alkaline solution of appropriate molar concentration and $\mathrm{Si} / \mathrm{Al}$ ratio and then cure it either in ambient temperature or increased one. As a binder researchers use different pozzolanic materials: metakaolin [3,4], fly ashes [5,6,7], slags 8 or mixes of abovementioned $[2,9]$. The reaction process needs an alkaline activator, among which the most popular are sodium or potassium silicates and sodium or potassium hydroxides $[5,6,7]$. The type of used

\footnotetext{
*Corresponding author: t.piotrowski@il.pw.edu.pl
} 
activator has a high influence on the raw materials dissolution of $\mathrm{Al}$ and $\mathrm{Si}$ ions. Jaarsveld and Deventer pointed out that using $\mathrm{NaOH}$ solutions in geopolymers binding process in comparison to $\mathrm{KOH}$ solutions results in higher degree of condensation, higher compressive strength, lower degree of crystallinity and acid resistance 10 . Using $\mathrm{NaOH}$ together with water glass, which increases the Si content in geopolymer mix, provides improvement in mechanical properties of the composite 11 . The most common $\mathrm{NaOH}$ molar concentration used in research is not higher than $20 \mathrm{M}$ with suggestion that sodium silicate to sodium hydroxide ratio should not exceed 1.012 .

Despite the fact, that foam concrete is not a subject of European standards, it is used in civil engineering. For example it is applied in sub-structures of industrial concrete floors [13] or as contact layer between concrete and subsoil [14]. The geopolymer foam composites present high potential as a low toxicity thermal insulation $[15,16]$ of low thermal conductivity (around $0.1 \mathrm{~W} /(\mathrm{m} \cdot \mathrm{K})$ ) depending on the used alkaline agent, foaming agent type and foaming agent mass ratio $[17,18]$. By foaming the geopolymer binder it is possible to obtain a composite with density lower than $1309 \mathrm{~kg} / \mathrm{m}^{3}$ [19]. Just like as in regular geopolymer binders, the curing temperature has an influence on the geopolymerization rate, enabling to produce more dense composite with higher compressive strength, lower water absorption and lower porosity [20].

In this study, the concept of geopolymer foam concrete is presented and analyzed. The granulated blast-furnace slag (GBFS) was alkali-activated and examined using compressive and flexural strength testing. The research seems to be important in terms of understanding possible production of lightweight foam concretes with geopolymer binders.

\section{Materials and Methods}

\subsection{Granulated Blast Furnace Slag (GBFS)}

The GBFS with high amorphous content (97.42\%), the chemical composition presented in tab. 1 (in conformity with EN 15671-1) was used as a binding material. This raw material with density of $3.001 \mathrm{~g} / \mathrm{cm}^{3}$ consists of coarse and fine particles with sharp edges. The median value of the particle size distribution adopted value of $21.44 \mu \mathrm{m}$ (see Fig. 1).

Table 1. GBFS description.

\begin{tabular}{|l|c|}
\hline $\begin{array}{l}\text { Chemical composition (\%) } \\
\text { and physical characteristic }\end{array}$ & GBFS \\
\hline $\mathrm{SiO}_{2}$ & 37.82 \\
\hline $\mathrm{Al}_{2} \mathrm{O}_{3}$ & 7.40 \\
\hline $\mathrm{Fe}_{2} \mathrm{O}_{3}$ & 0.85 \\
\hline $\mathrm{MnO}$ & 0.17 \\
\hline $\mathrm{MgO}$ & 6.34 \\
\hline $\mathrm{CaO}$ & 44.05 \\
\hline $\mathrm{Na} \mathrm{N}_{2} \mathrm{O}$ & 0.20 \\
\hline $\mathrm{K}_{2} \mathrm{O}$ & 0.28 \\
\hline $\mathrm{TiO}_{2}$ & 0.26 \\
\hline $\mathrm{P}_{2} \mathrm{O}_{5}$ & 0.05 \\
\hline $\mathrm{LOI}$ & 0.00 \\
\hline $\mathrm{Total}_{2}$ of $\mathrm{XRF}^{2}$ & 97.42 \\
\hline$\sum\left(\mathrm{SiO} \mathrm{Al}_{2}+\mathrm{O}_{3}+\mathrm{Fe}_{2} \mathrm{O}_{3}\right)$ & 46.02 \\
\hline $\mathrm{Real}$ density $\left(\mathrm{g} / \mathrm{cm}^{3}\right)$ & 3.001 \\
\hline Median particle size $(\mu \mathrm{m})$ & 21.44 \\
\hline Amor. & 92.79 \\
\hline
\end{tabular}

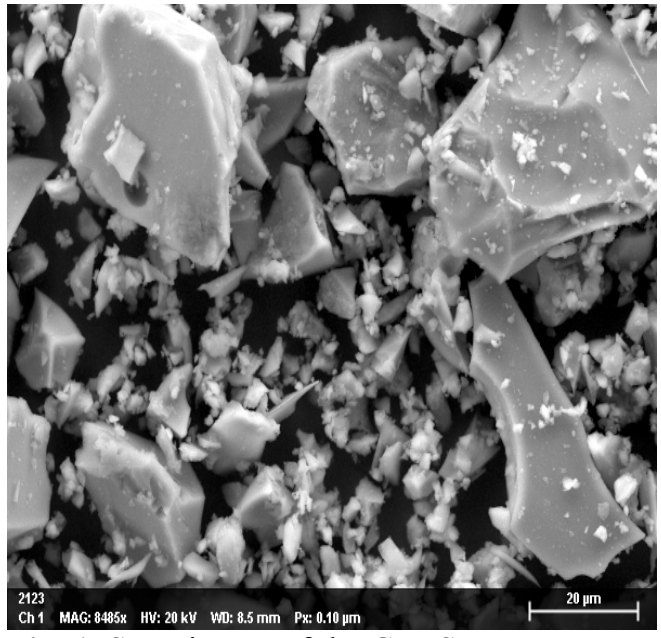

Fig. 1. SEM image of the GBFS. 


\subsection{Alkaline activators}

Two types of alkaline activators were used in geopolymer foam concrete production: the sodium silicate and the sodium hydroxide. The aqueous hydroxide solution was prepared with sodium hydroxide pellets and water. Additionally sodium silicate of molar module: 2,5 $+/-0,1$ and minimum oxides content $39 \%$ was used.

\section{Mixture Properties and Experimental Methodology}

All the samples were made with variable amount of water with other parameters ceteris paribus (mixture proportions presented in Table 2.). Initial assumptions for mix composition based on J. Provis and H. Wang article [22], where the amount of raw material and activators was constant in the geopolymer production, changing only the water content. Following the standard ASTM C796-97 the foaming solution in the foam was considered as part of the total mixing water. The calculated total mixing water to slag ratio (w/s) was from 0.29 to 0.37 . The pre-foaming method, a common one for foamed concrete production, was used. The foam was prepared separately with Meex AG foaming agent and Idrobase foam nebuliser (PS 8 bar). The $\mathrm{NaOH}$ water solution, sodium silicate and GBFS were mixed in a hand held mixing stirrer to create geopolymer paste. Then the foam was gently added and mixed to avoid occurrence of bubbles with large diameter. $10 \mathrm{~cm}$ cubes and $4 \times 4 \times 16 \mathrm{~cm}$ beams were casted and left for $48 \mathrm{~h}$ before demolding. The samples were cured in the ambient conditions till testing after 90 days. The compressive and flexural strength were measured in accordance with EN 196-1 and EN 12390-3.

Table 2. Mix composition.

\begin{tabular}{|c|c|c|c|c|c|c|}
\hline Symbol & $\begin{array}{c}\text { GBFS } \\
{[\mathbf{g}]}\end{array}$ & $\begin{array}{c}\text { NaOH } \\
\text { pellets } \\
{[\mathbf{g}]}\end{array}$ & $\begin{array}{c}\text { Water } \\
\text { [g] }\end{array}$ & $\begin{array}{c}\text { Sodium } \\
\text { silicate[g] }\end{array}$ & $\begin{array}{c}\text { Foam } \\
{[\mathbf{g}]}\end{array}$ & $\begin{array}{c}\text { w/s } \\
\text { ratio }\end{array}$ \\
\hline GFC_029 & 8000 & 432 & 801.33 & 2116.8 & 240 & 0.29 \\
\hline GFC_033 & 8000 & 432 & $801.33+320.59$ & 2116.8 & 240 & 0.33 \\
\hline GFC_037 & 8000 & 432 & $801.33+640.59$ & 2116.8 & 240 & 0.37 \\
\hline
\end{tabular}

\section{Experimental Results and Discussions}

Figure 2 presents influence of w/s ratio on the volume density. It is observed that increase of total water amount decompose foam during mixing and forming. The specimens with high $\mathrm{w} / \mathrm{s}$ have density close to standard geopolymer paste [21] approx. $1.8 \mathrm{~g} / \mathrm{cm}^{3}$ and do not present porous structure as it is clearly visible on the cross section of the GFC_029 (see Fig.3). 


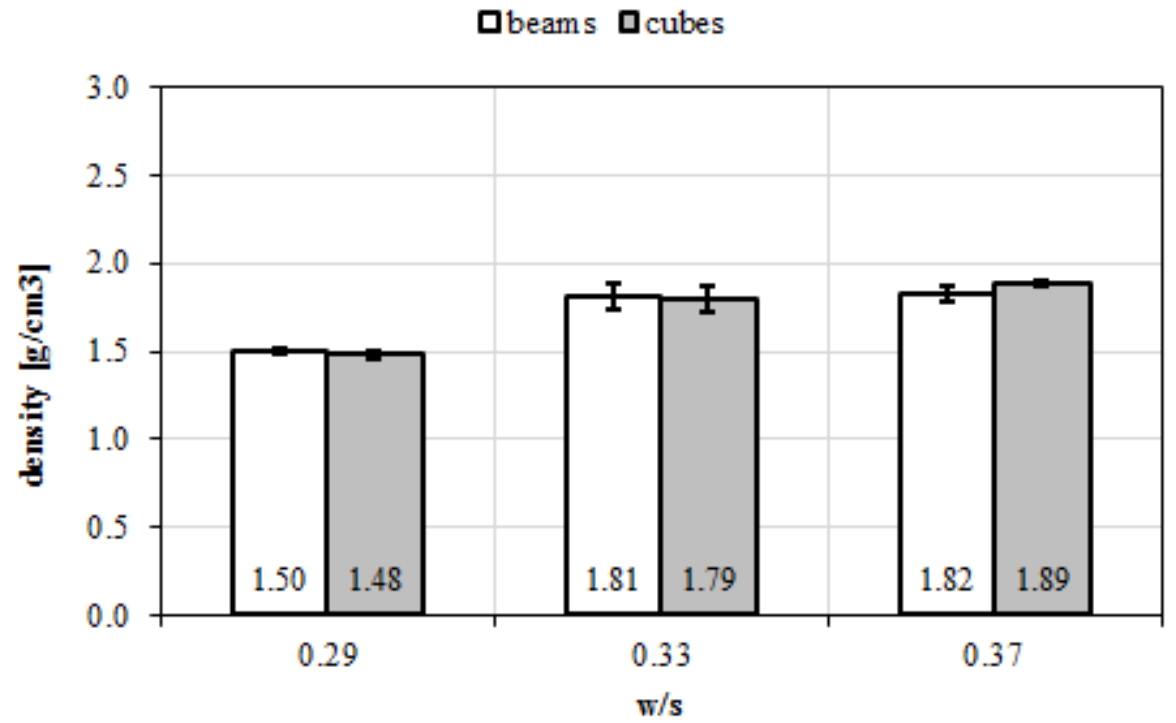

Fig. 2. Density of the cubes and beams with different $w / s$ ratio.

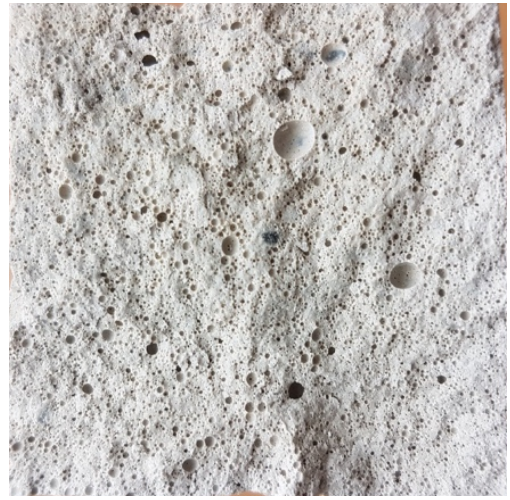

Fig. 3. Cross section of specimen $\mathrm{w} / \mathrm{s}=0.29$.

Figures 4 and 5 present changes in flexural and compressive strength depending on the w/s ratio. The level of flexural strength value for all the specimens were between 2 and 3 $\mathrm{MPa}$ that is comparable to regular cement pastes. The GFC 029 specimen of the most porous structure obtained the lowest compressive strength value (22.2 MPa for beams and $18.1 \mathrm{MPa}$ for cubes). The maximum compressive strength was gained for GFC_033 (51.8 MPa for beams and $44.1 \mathrm{MPa}$ for cubes). It should be stressed that their densities were only $1.8 \mathrm{~g} / \mathrm{cm}^{3}$. When comparing compressive strength results for the GFC_033 and GFC_037 samples with less porous structure, the common relation for cement based composites is observed - a water to binder ratio increase makes a compressive strength decrease. It is probably caused by higher shrinkage, causing cracks and microstructure defects. Nevertheless their compressive strengths are higher than for regular cement pastes. 


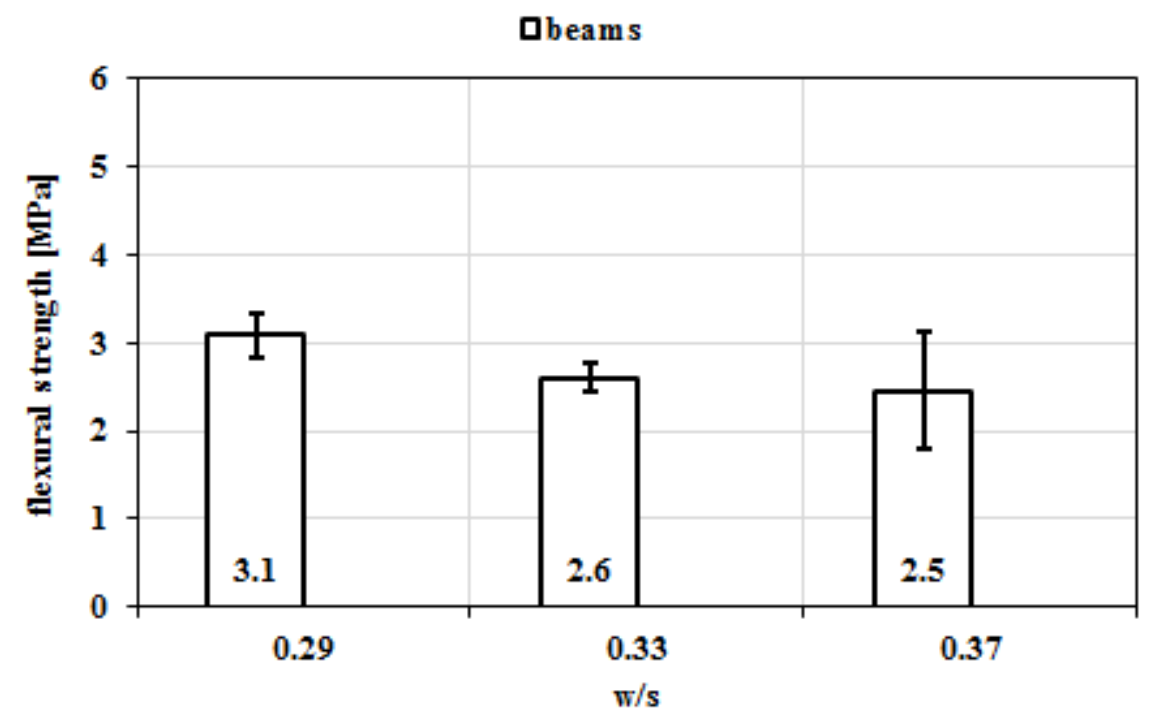

Fig. 4. Flexural strength of the beams with different w/s ratio.

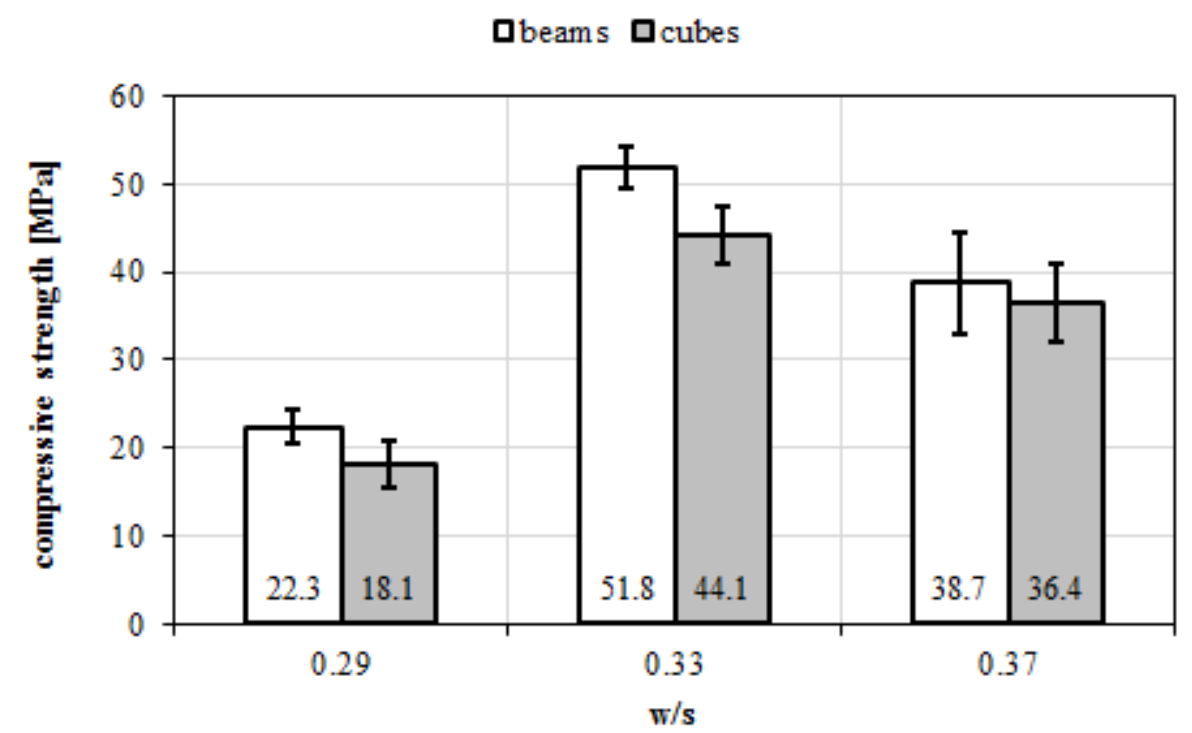

Fig. 5. Compressive strength of the beams and cubes with different w/s ratio.

\section{Conclusions}

The foam concrete is a material sensitive to water overdosing that can decompose foam during mixing and forming. Specimens with $\mathrm{w} / \mathrm{s}=0.29$ ratio have porous structure, the lowest density $1.500 \mathrm{~g} / \mathrm{cm}^{3}$ and relatively high compressive strength (around $20 \mathrm{MPa}$ ). The highest values of compressive strength were obtained in case of specimens of $\mathrm{w} / \mathrm{s}=0.33$ ratio but at the same time the porous structure was not observed. Further increase of w/s ratio does not 
influence the density but creates a decrease in compressive strength value. This preliminary investigation showed a big potential of geopolymer foam concrete furthermore, the research on this subject will be continued.

The results were obtained in the Karol Nizio bachelor thesis. Research was supported by Warsaw University of Technology.

\section{References}

1. J. Davidovits, Geopolymers. Chemistry \& Application (Institut Geopolymere, France 2011)

2. S. Puligilla, P. Mondal, Cem. Concr. Res. 43, 70 (2013)

3. M. Zhang, Cem. Concr. Comp. 78, 21 (2017)

4. P. He, M. Wang, S. Fu, D. Jia, S. Yan, J. Yuan, J. Xu, P. Wang, Y. Zhou, Ceram. Int. 42, 14416 (2016)

5. Y. Hou, D. Wang, W. Zhou, H. Lu, L. Wang, J. Wuhan Univ. of Technology- Mater. Sci. Ed. 24, 771 (2009)

6. M.G. Canfield, J. Eicher, K. Griffith, D.J. Hearn, J. Mater. Sci. 49, 5922 (2014)

7. G.S. Ryu, Y.B. Lee, K.T. Koh, Y.S. Chung, Constr. Build. Mater. 47, 409 (2013)

8. M.A. Qidwai, J. Eng. Res. Studies VI, 6 (2015)

9. P. Nath, P.K. Sarker, Constr. Build. Mater. 66, 163 (2014)

10. J. Van Jaarsveld, J. Van Deventer, Eng. Chem. Res. 38, 3932 (1999)

11. F. Pacheco-Torgal, J. Castro-Gomes, S. Jalali, Constr. Build. Mater. 22, 1315 (2008)

12. M.S. Morsy, S.H. Alsayed, Y. Al-Salloum, T. Almusallam, Arab. J. Sci. Eng. 39, 4333 (2014)

13. M. Kadela, M. Kozłowski Procedia Eng. 161, 468 (2016)

14. M. Kadela, B Pol Acad. Sci-Tech. 64, 751 (2016)

15. Z. Zhang, J.L. Provis, A. Reid, H. Wang, Constr. Build. Mater. 56, 113 (2014)

16. D. Shi, L. Shi, J. Zhang, J. Cheng, Adv. Mater. Res. 450-451, 1504 (2012)

17. Z. Abdollahnejad, F. Pacheco-Torgal, T. Félix, W. Tahri, J.B. Aguiar, Constr. Build. Mater. 80, 18 (2015)

18. V. Vaou, D. Panias, Miner. Eng. 23, 1146 (2010)

19. J.G. Sanjayan, A. Nazari, L. Chen, G.H. Nguyen, Constr. Build. Mater. 79, 236 (2015)

20. M.M. Al Bakri Abdullah, K. Hussin, M. Bnhussain, K.N. Ismail, Z. Yahya, R.A. Razak, Int. J. Mol. Sci. 13, 7186 (2012)

21. D.L.Y. Kong, J.G. Sanjayan, Cem. Concr. Res. 40, 334 (2010)

22. J. Provis, H. Wang, Cem. Concr. Comp. 62, 97 (2015) 